\title{
Changing epidemiology of SARS-COV in the context of COVID-19 pandemic
}

\author{
S. BHATTACHARYA ${ }^{1}$, P. BASU ${ }^{2}$, S. PODDAR ${ }^{3}$ \\ ${ }^{1}$ Department of Zoology, Asutosh College, University of Calcutta, India; ${ }^{2}$ Tomas Bata University in Zlin, Czech Republic; \\ ${ }^{3}$ Lincoln University College, Malaysia
}

Keywords

COVID-19 $\bullet$ SARS-CoV $\bullet$ Changing epidemiology $\bullet$ Evolution

\section{Summary}

\begin{abstract}
SARS-CoV-2 is a new form of $\beta$-coronavirus that has been recently discovered and is responsible for COVID 19 pandemic. The earliest infection can be traced back to Wuhan, China. From there it has spread all over the world. Keeping in view the above perspective, an attempt is made in order to find out the epidemiological pattern of COVID 19 pandemic, if any, in different geoclimatological regions of the world in terms of case incidence and mortality. This study is also an endeavor to review and analyze the gradual changes of the genetic makeup of SARS-CoV from evolutionary and epidemiological perspectives. The raw data of COVID-19 cases and death incidences were collected from the World Health Organization (WHO) website from the time period: $1^{\text {st }}$ April to $6^{\text {th }}$ April, 2020. The data that are utilized here for general and Case fatality rate (CFR) based analysis. Western pacific region, European region and Americas have the greatest number
\end{abstract}

\section{Introduction}

Coronavirus $(\mathrm{CoV})$ is a positive single stranded RNA virus which causes a respiratory tract infection in human [1]. Earlier in 2002 and 2012, the emergence of severe acute respiratory syndrome (SARS) coronavirus (SARS-CoV) and Middle East respiratory syndrome (MERS) coronavirus (MERS-CoV) have attracted the researchers to explore the epidemic potential [1] of these viruses. A newly discovered $\beta$-coronavirus led to the occurrence of a number of pneumonia cases in Wuhan, China, in December 2019. Initially (on 12 January 2020), it was given the name, the 2019-novel coronavirus (2019-nCoV) by the World Health Organisation (WHO). Later, the disease was officially renamed as coronavirus disease 2019 (COVID-19) by WHO. The new coronavirus was termed as SARS-CoV-2 by the Coronavirus Study Group (CSG) of the International Committee, on 11 February 2020 [2]. The SARS-CoV-2 also develops an upper respiratory tract infection much alike its earlier ancestor SARS-CoV, however, the recent pandemic due to this novel mutated SARS-CoV-2 virus infection created a critical pandemic situation throughout the globe [3]. Until now, different researches are being performed to understand the infection severity and virus transmissibility of novel SARS-CoV-2. Keeping in view the above perspective, an attempt is made in order to find of infected cases $(P<0.001)$; whereas deaths have been found to be significantly higher in Europe $(P<0.001)$. Total number of confirmed cases and deaths in south-east Asia are comparatively lower $(P<0.001)$. Case fatality rate $(C F R)$ has also found significant for European region. SARS-CoV-2 is considered to be a strain of SARS-CoV that has a high rate of pathogenicity and transmissibility. Result indicated that the European region has been affected mostly for both cases and death incidences. The novel mutations in SARS-CoV-2 possibly increase the virus infectivity. Genetic heterogeneity of this virus within the human population might originate as the representatives of naturally selected virus quasispecies. In this context, the presence of the asymptomatic individuals could be a significant concern for SARS-CoV-2 epidemiology. Further studies are required to understand its genetic evolution and epidemiological significance.

out the epidemiological pattern of COVID-19 pandemic, if any in different geo-climatological regions of the world in terms of case incidence and mortality. In addition, this study is also an endeavor to review and analyze the gradual changes of the genetic makeup of SARS-CoV from evolutionary and epidemiological perspectives.

\section{CORONAVIRUS (COV) AND ITS CHARACTERISTICS}

Coronaviruses are non-segmented, enveloped and positive sense single-stranded RNA virus genomes. They have a size ranging from 26 to 32 kilobases. The virion consists of a nucleocapsid composed of genomic RNA and phosphorylated nucleocapsid $(\mathrm{N})$ protein, covered by two different types of spike proteins: the hemagglutinin-esterase (HE) (found in some CoVs) and the spike glycoprotein trimmer (S) (found in all $\mathrm{CoVs}$ ). The $\mathrm{S}$ protein in the virus envelop consists of the membrane (M) protein and the envelope (E) protein [2]. The $\alpha, \beta, \gamma$ and $\delta$ coronaviruses are the four genera into which the coronavirus subfamily is genotypically and serologically divided [4]. Gastroenteritis in animals and respiratory illness in humans are caused by $\alpha$-coronaviruses and $\beta$-coronaviruses. The two deadly and extremely pathogenic $\beta$-coronaviruses and 2002 SARS-CoV and the 2012 MERS-CoV, cause severe respiratory diseases in humans. HCoV-NL63 and HCoV$229 \mathrm{E}$, the $\alpha$-coronaviruses and HCoV-OC43 and HKU1, 
the $\beta$-coronaviruses, are the four human coronaviruses that cause mild upper respiratory syndromes in immunocompetent hosts, though severe infections can be caused by few of them in infants, young children, elderly people and immune-compromised individuals [5-7]. The majority COVID-19 infection remains asymptomatic or mild. The non-SARS like CoVs are responsible for upper respiratory tract $(20 \%)$ infections in adult individuals. However, these non-SARS like CoVs are often associated with severe acute respiratory illness (SARI) in elderly people and immunosuppressed individuals [8]. All human coronaviruses are considered to have an animal origin, according to the recent sequence databases. Among them, SARS-CoV, MERS-CoV, SADS, HCoVNL63 and HCoV-229E are recognized to have an origin in bats, while HCoV-OC43 and HKU1 are considered to have an origin in rodents [5]. The zoonotic transmission of virus from natural hosts to humans may certainly be carried out by domestic animals that portray an important part as intermediate hosts. These domestic animals can also be infected by spillover of the diseases caused by bat-borne or closely related coronaviruses [5, 9, 10]. The SARS-CoV-2 is also considered to have a zoonotic origin and has a close genetic resemblance to the bat coronaviruses that suggests it has emerged as a bat-borne virus [11, 12]. Additionally, introduction to humans is also thought to be brought about by pangolin that serves as an intermediate animal reservoir [13]. Several dogs and cats (domestic cats and a tiger) have tested positive to COVID-19 virus following close contact with infected humans [14].

\section{SARS-CoV-2 AND COVID-19}

On 11 February 2020, the International Committee of Taxonomy of Viruses (ICTV) announced that, the differences between 2019-nCoV and the virus strain from the 2003 SARS outbreak were not enough to declare them to be separate viral species; as per the rules that calculate hierarchical relationships among different coronaviruses on the basis of five conserved nucleic acid sequences. Hence, 2019-nCoV was identified as a Severe Acute Respiratory Syndromerelated Coronavirus. Taxonomically, SARS-CoV-2 was thus declared to be a strain of SARS-CoV-2 [15] which is responsible for COVID-19. The genome of the coronaviruses is seen to contain variable numbers (6-11) of open reading frames (ORFs) [11]. 16 nonstructural proteins (NSP) are encoded by two-thirds of viral RNA located in the first ORF. The spike (S) glycoprotein, small envelope (E) protein, matrix (M) protein, nucleocapsid $(\mathrm{N})$ protein and many accessory proteins are encoded by the viral genome that play an important role in the host innate immune response [2, 5]. Certain degree of similarity has been found in the S-glycoprotein gene and receptor-binding domain (RBD) of SARS-CoV-2 and SARS-CoV. This explains the capability of direct human transmission of SARS-CoV-2 [5]. High infectious capability of SARS-CoV-2 is attributed by novel mutations in their non-structural proteins. Two predominant evolvement types of SARS-CoV-2 include the L type $(\sim 70 \%)$ and the $S$ type $(\sim 30 \%)$ strains. The $L$ type strains have derived from the $S$ type and are more aggressive and contagious, evolutionarily [16].

\section{ASPECTS OF SARS-CoV-2 INFECTION}

SARS-CoV uses ACE2 as its cellular receptor, which is found in the lower respiratory tracts of humans. It has also been confirmed that SARS-CoV-2 also uses the same cellular receptor, ACE2, to gain entry into the host cells. The S-glycoprotein on the surface of the coronavirus can attach to ACE2 on the surface of the human cells [2, 12]. Among all the known $\beta$-coronaviruses, SARS-CoV-2 is distinct because of the presence of two of the most important genomic factors that increase the pathogenicity and transmissibility of the virus (Fig. 1):

1. polybasic furin cleavage site and O-linked glycans: A polybasic cleavage site is present at the junction of $\mathrm{S} 1$ and S2, the two spike subunits, in SARS-CoV-2. Thus, furin and other proteases can carry out effective cleavage, which in turn plays a major role in establishing viral infectivity and host range;

2. mutations in the receptor binding domain (RBD) of SARS-CoV-2. The most flexible part of the coronavirus genome is the RBD in the spike protein. The RBD of SARS-CoV-2 binds with high affinity to the ACE2 of humans, ferrets, cats and other species with high receptor homology $[17,18]$.

\section{Materials and methods}

The raw data of COVID-19 cases and death incidences were collected from the World Health Organization (WHO) website [19]. Data that are utilized here for analysis were taken from the time period: $1^{\text {st }}$ April to $6^{\text {th }}$ April, 2020. These were initially arranged in groups according to different geo-climatic regions. Then the case fatality rate (CFR) is calculated by the following way:

\section{Number of death incidence/ total number of case incidence $* 100 \%$}

Statistical differences between standard error of the means (SEM) of the studied groups were assessed using one-way analysis of variance (ANOVA) followed by suitable post-hoc test (i.e. Bonferroni test). Level of statistical significance is expressed through the P-value: $\mathrm{P}<0.001, \mathrm{P}<0.01$ and $\mathrm{P}<0.05$.

\section{Results}

It can be seen from Figure 2, that Western Pacific region, European region and Americas have the greatest number of infected cases $(\mathrm{P}<0.001)$; whereas deaths have been found to be significantly higher in Europe $(\mathrm{P}<0.001)$. On the other hand, the total number of confirmed cases and deaths in South-Eastern Asia are comparatively 
Fig. 1. Major structural characters of SARS-COV-2 [17].

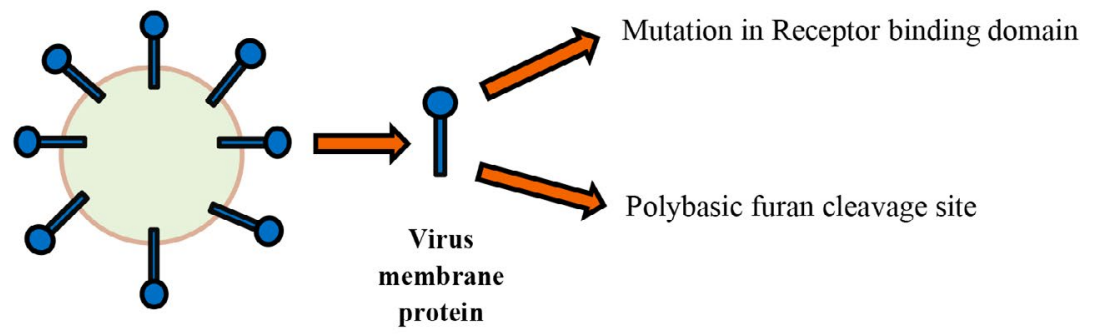

SARS- CoV2

(Diagrammatic representation)

Fig. 2. Effect of COVID-19 on human population. A) total number of confirmed COVID 19 cases; B) total number of deaths in different regions within the globe from $1^{\text {st }}$ to $6^{\text {th }}$ April, 2020; C) Case Fatality Rate $(\%)$ of COVID-19 on $6^{\text {th }}$ April, 2020. Bars indicate percentage of statistical errors of the CFR data [19].
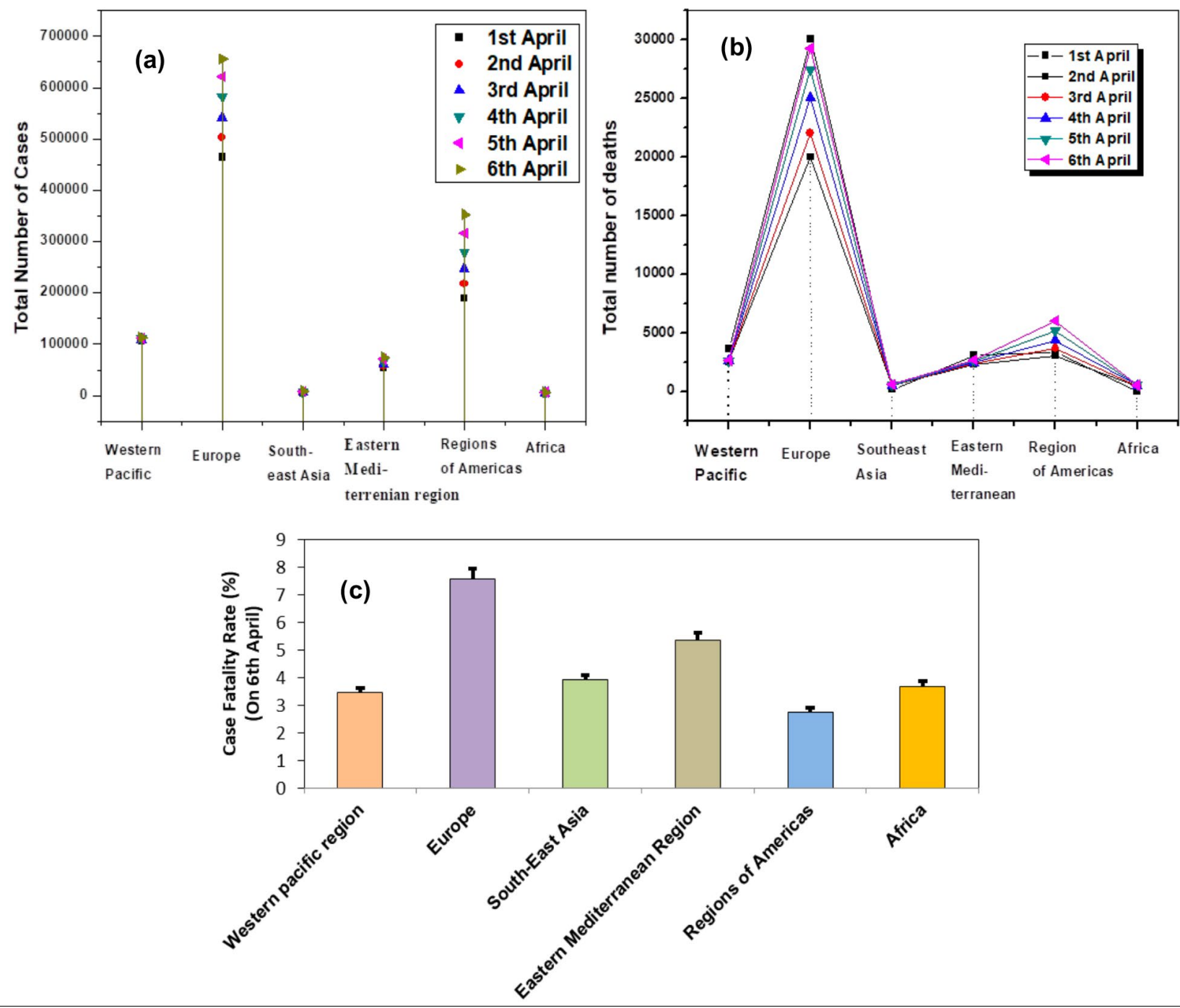

lower than that of Europe and America $(\mathrm{P}<0.001)[19]$ (Fig. 2). Case fatality rate (CFR) was also found to be significant for European region. Hence, it has been clearly seen that the European region have been affected mostly $(\mathrm{P}<0.001)$ with respect to the number of cases and deaths. This disease severity might be linked to the genetic uniqueness of the mutated SARS-CoV-2.

\section{Discussion}

Epidemiological study from the result section indicates COVID-19 cases and deaths are significant in both European and American region. This global pandemic situation due to COVID-19 is caused by SARS$\mathrm{CoV}-2$, which is a new form of $\beta$-coronavirus that has 
Tab. I. COVID-19 cases comparison between different geographical regions (from $1^{\text {st }}$ to $6^{\text {th }}$ April 2020) [19].

\begin{tabular}{|l|c|c|}
\hline Geographical regions & COVID-19 cases & Affected age groups \\
\hline Western Pacific and Europe & Significant in Europe $(P<0.001)$ & \\
\hline Western Pacific and Southeast Asia & Significant in Western Pacific $(P<0.01)$ & \multirow{2}{*}{50 -80 years } \\
\cline { 1 - 2 } Western Pacific and Regions of Americas & Significant in region of Americas $(P<0.001)$ & \\
\cline { 1 - 2 } Western Pacific and Africa & Significant in Western Pacific $(P<0.001)$ & \\
\cline { 1 - 2 } Europe and South East Asia, Region of Americas, & Significant in Europe $(P<0.001)$ & \\
\cline { 1 - 2 } $\begin{array}{l}\text { Region of Americas and Southeast Asia, Africa, } \\
\text { Eastern Mediterranean }\end{array}$ & Significant in region of Americas $(P<0.001)$ & \\
\hline
\end{tabular}

Tab. II. Comparison of death incidences due to COVID-19 between different geographical regions (from $1^{\text {st }}$ to $6^{\text {th }}$ April 2020) [19].

\begin{tabular}{|l|c|c|}
\hline Geographical regions & Deaths due to COVID-19 & $\begin{array}{c}\text { Mostly affected age } \\
\text { group }\end{array}$ \\
\hline \begin{tabular}{l|c|} 
Europe and Western Pacific, South East Asia, \\
Region of Americas, Eastern Mediterranean, Africa
\end{tabular} & Significant in Europe $(P<0.001)$ & \multirow{2}{*}{ Over 60 years } \\
\cline { 1 - 2 } South East Asia and region of Americas & Significant in region of Americas $(P<0.05)$ & \\
\hline Region of Americas and Africa & Significant in region of Americas $(P<0.05)$ & \\
\hline
\end{tabular}

been recently discovered. SARS-CoV-2 is considered to be a strain of SARS-CoV that has a high rate of pathogenicity and transmissibility. European countries have been affected severely (cases and deaths) by the virus than the other regions (Tabs. I, II). The highest death rate has been found significant between 50-80 years of age [19] (Tab. II). The mutation in the receptor binding domain and the polybasic furin cleavage site on the spike protein might be the major contributor of the significant infectivity and transmissibility to the virus. However, research indicated that different transition type of point mutation causes the virus heterogeneity in different geographical regions [20]. These ultimately affect the virus infectivity. Interestingly, the individuals over 60 years are developing severe pneumonia [21]. This might be due to the genetic structure of the virus which affects the low immunity of elderly individuals. However, different immune-pathological factors can also play a role in this. The exact process of affecting the immune system by SARS-CoV-2 is still unclear, however it can be said that virus like SARS-CoV after entering into human body is recognized by different receptors (like Toll Like Receptor [TLR], Pattern Recognition Receptor [PRR]) and induces response like expression of inflammatory factors, synthesis of type I interferon. In this context, it is relevant to mention that SARS-CoV has the ability to bypass this strong immunological barrier through the activity of its $\mathrm{N}$ protein. This supports the high infectivity of the virus [21].

The significant cases and deaths found throughout the different geo-climatic regions (i.e. Western Pacific, Europe, America, Eastern Mediterranean, South East Asia) due to SARS-CoV-2 is potentially caused by mutational changes in the virus genome. The novel mutations in SARS-CoV-2 possibly increase the virus infectivity through the introduction of unique mutations in their RNA genome. It has been found that there are ninetythree mutations are present in the entire genome of SARS-CoV-2. Among them, 42 missense mutations are found within the non-structural and structural protein of the virus. In addition, 29 and 8 missense mutations were located in the ORF1ab polyprotein region and spike protein [22]. However, the mutation in the receptor binding domain and the polybasic furin cleavage site on the spike protein might be the major contributor of the significant infectivity and transmissibility to the virus. The significant cases of COVID-19 throughout different climatic regions possibly indicate the SARS-CoV-2 RNA genome fitness. In this context, virus quasispecies might play a significant role in virus heterogeneity. It has been stated that, RNA virus quasispecies could successfully bypass host immune system and its response; which might further increase the genetic diversity of the virus [23, 24]. This viral RNAs of the quasispecies from naturally "fit" RNA virus population will increase the potential risk of infection and disease severity [23], which could ultimately affect the known face and nature of SARS-CoV epidemiology.

The high CFR and case incidences in European and American regions indicate the disease severity of COVID-19. This disease severity could also be attributed to antibody-dependent enhancement phenomenon (ADE). ADE is caused by non-neutralizing antiviral proteins that facilitate virus entry into the host cells, causing enhanced infectivity in the cells [25]. In case of ADE, a high-affinity memory $\mathrm{B}$ cell, specific for a particular virus (For eg, Virus A), is preferentially activated by a new serotype of the virus (For eg, Virus A1), to produce antibodies that bind ineffectively to this new serotype. The presence of these ineffective antibodies inhibits activation of naive B cells that could produce more effective antibodies against the new serotype. This causes a reduced immune response against the new serotype and increases the potential for serious infection. This condition has already been reported in case of other RNA viruses like Dengue virus. Four antigenically different serotypes of dengue virus (1-4) exist. Infection with one serotype leads to the production of neutralizing homotypic IgG antibodies that provide lifelong immunity against that particular serotype. The phenomenon of ADE is seen when a different serotype of the dengue virus infects a person within months or 
years of the first infection by a serotype different from the currently infecting one. In such cases, the clinical manifestations of the secondary infection are much more severe than the primary infection [26]. Study indicated that coronavirus like HCoV NL63 has been circulating in human population for centuries and this virus and SARS-CoV-2 are possible serotypes which are using similar mechanism for the cell entry $[4,27]$, thus this ADE phenomenon might play an important role in increasing the SARS-CoV-2 infectivity and disease severity leading to COVID-19 pandemic.

In the context of disease severity and epidemiological complexity, the asymptomatic cases have the notable importance. Recent research indicated that $1-2 \%$ of the cases in the Chinese population during COVID-19 were asymptomatic [28]. It has been documented that, as of February 11, 2020, there were 72, 314 cases probably involves the asymptomatic individuals [29]. These asymptomatic cases are associated with mild COVID-19 symptoms. The development of a significant viral load within the asymptomatic human individual could further facilitate the virus transmission and thereby complicate the disease situation. Thus, in depth study is required to understand the behavior and role of asymptomatic cases in COVID-19 pandemic.

On the other hand, the higher COVID-19 death incidences were often associated with the complex response of human immune system. It has been found that patients with COVID-19 are often associated with cytokine storm syndrome. This is a systemic inflammatory response of the innate immune system in response to a bacterial/viral infection which can lead to multi organ failure [21, 30]. Research indicated that one of the reasons of the significant mortality in COVID-19 is hyper-inflammation and lung injury which might be caused from the "cytokine storm" effect [30]. This observation can be correlated with the fact that, COVID-19 causes notable mortality to elder groups throughout the world as elder people are much more prone to respiratory inflammatory problems which could ultimately lead to lung injury. The high case incidence of COVID-19 in western part of world (i.e. Europe and America) compared to the South East Asia and Western Pacific indicates that the temperature might play a significant role in $\mathrm{CoV}$ infection. Research demonstrated that SARS-CoV2 is notably stable in low temperature like $4^{\circ} \mathrm{C}$ [31]. This observation can be correlated with the prevalence of COVID-19 cases and deaths in the temperate regions of Europe. However, the tropical regions like south-east Asia have also shown notable COVID-19 cases, which left the further possibility of research in this direction.

\section{Conclusions}

COVID-19 has become a pandemic, which leads to the death of large individuals of the entire population of Earth. SARS-CoV-2 is a novel virus which harbors significant genetic mutations that are completely new to the innate immune system of the human population. Thus, this virus was capable of affecting a large section of the human populations. Western pacific region, European region and Americas have the greatest number of infected cases. European region has been affected mostly for both cases and death incidences. SARS-CoV-2 is the highly contagious representative of coronavirus that contains mutated genomic content. This mutation might play a key role in the directional selection of this group of viruses in their evolution. The recent researches of virus heterogeneity across the continents probably indicate the probable existence and role of viral quasispecies, shaping and facilitating the natural selection of the coronavirus and thereby facilitate further emergence as a novel mutated virus which can adapt to the different eco-climatic regions. This can be supported by recent research where different subtypes of the virus have been found responsible for the infection. The presence of the asymptomatic individuals could further be a significant concern for SARS-CoV-2 epidemiology. As the asymptomatic person will act as a carrier for the virus, determination and isolation of the symptomatic patients will not be helpful to manage this present epidemic. Thus, sustained testing for the virus infection is recommended largely by the scientific community. On the other hand, asymptomatic carriers could play a notable role as a "mixing pot" for the virus subtypes and thus might develop different viral strain within the human body. RNA virus infections involve an "amplification host" which amplifies the virus. These asymptomatic SARS-CoV carriers could possibly act as both, "amplifying host" and "mixing pot" and may create a more complex epidemiological situation. However, more studies are required in this direction to prove this hypothesis. Undoubtedly, SARS-CoV-2 is a virus with altered genetic makeup and this introduces a selection pressure to the human immune system. Hence, over a period of time, herd immunity can become an important phenomenon to reduce the severity of the virus. However, this will be a time-dependent phenomenon. On the other hand, the continuous genetic mapping is required which will elaborate the understanding of the virus "mutation spectrum" that will further facilitate the development of a vaccine. Further studies with deep genomic sequencing and identification of mutations are required to understand the evolving faces of SARS-CoV and its epidemiological significance.

\section{Acknowledgements}

The authors extend their gratitude to Prof. A.K. Hati, Ex-Director of Calcutta School of Tropical Medicine, India for his kind suggestion and Prof. Apurba Ray, Vice Principal, Asutosh College, Kolkata, India for his kind support during the work. Second author extends his gratitude to Assoc. Prof. Nabanita Saha, Prof. Petr Saha and the Rector of Tomas Bata University in Zlin, Czech Republic for their kind support. 
Funding sources: this research did not receive any specific grant from funding agencies in the public, commercial, or not-for-profit sectors.

\section{Conflict of interest statement}

The authors declare no conflict of interest.

\section{Authors' contributions}

Conceptualization: $\mathrm{PB}$ and SB; methodology: $\mathrm{PB}$; data analysis, interpretation and representation: $\mathrm{PB}$; preparation of initial draft of manuscript: $\mathrm{PB}$; editing: PB, SB, SP; Supervision: PB.

\section{References}

[1] Raoult D, Zumla A, Locatelli F, Ippolito G, Kroemer G. Coronavirus infections: epidemiological, clinical and immunological features and hypotheses. Cell Stress 2020,4:6675. https://doi.org/10.15698/cst2020.04.216

[2] Guo Y-R, Cao Q-D, Hong Z-S, Tan Y-Y, Chen S-D, Jin H-J, Tan $\mathrm{K}-\mathrm{S}$, Wang D-Y, Yan Y. The origin, transmission and clinical therapies on coronavirus disease 2019 (COVID-19) outbreak an update on the status. Mil Med Res 2020;7:2-10. https://doi. org/10.1186/s40779-020-00240-0

[3] Chatterjee R, Bhattacharya S. Could novel coronavirus (Sars-Cov-2) be the evolving face of a new generation of genetically complex epidemiological challenge? Malays J Med Res 2020;4:49-52. https://doi.org/10.31674/mjmr.2020. v04i02.007

[4] Li G, Fan Y, Lai Y, Han T, Li Z, Zhou P, Pan P, Wang W, Hu $\mathrm{D}$, Liu X, Zhang Q, Wu J. Coronavirus infections and immune responses. J Med Virol 2020;92:424-32. https://doi.org/10.1002/ jmv. 25685

[5] Cui J, Li F, Shi, Z-L. Origin and evolution of pathogenic coronaviruses. Nat Rev Microbiol 2019;17:181-92. https://doi. org/10.1038/s41579-018-0118-9

[6] Forni D, Cagliani R, Clerici M, Sironi M. Molecular evolution of human coronavirus genomes. Trends Microbiol 2017;25:3548. https://doi.org/10.1016/j.tim.2016.09.001

[7] Su S, Wong G, Shi W, Liu J, Lai ACK, Zhou J, Liu W, Bi Y, Gao, GF. Epidemiology, genetic recombination, and pathogenesis of coronaviruses. Trends Microbiol 2016;24:490-502. https://doi. org/10.1016/j.tim.2016.03.003

[8] Paules CI, Marston HD, Fauci AS. Coronavirus infections-more than just the common cold. JAMA 2020;328:707. https://doi. org/10.1001/jama.2020.0757

[9] Lacroix A, Duong V, Hul V, San S, Davun H, Omaliss K, Chea S, Hassanin A, Theppangna W, Silithammavong S, Khammavong K, Singhalath S, Greatorex Z, Fine AE, Goldstein T, Olson S, Joly DO, Keatts L, Dussart P, Afelt A, Frutos R \& Buchy P. Genetic diversity of coronaviruses in bats in Lao PDR and Cambodia, Infect. Genet. Evol 2017, 48:10-18. https://doi. org/10.1016/j.meegid.2016.11.029.

[10] Simas, PVM, de Souza Barnabe, AC, Durães-Carvalho, R, de Lima Neto, DF, Caserta, LC, Artacho, L, Jacomassa, FAF, Martini, MC, dos Santos, MMAB, Felippe, PAN, Ferreira, $\mathrm{HL}$, Arns CW. Bat coronavirus in Brazil related to appalachian ridge and porcine epidemic diarrhea viruses. Emerg Infect Dis 2015;21:729-31. https://doi.org/10.3201/eid2104.141783

[11] Song Z, Xu Y, Bao L, Zhang L, Yu P, Qu Y, Zhu H, Zhao W, Han Y, Qin C. From SARS to MERS, thrusting coronaviruses into the spotlight, Viruses 2019;11:E59. https://doi.org/10.3390/ v11010059

[12] Zhou P, Yang XL, Wang XG, Hu B, Zhang L, Zhang W,Si H-R, Zhu Y, Li B, Huang C-L, Chen H-D, Chen J, Luo Y, Guo H, Jiang R-D, Liu M-Q, Chen Y, Shen XR, Wang X, Zheng X-S, Zhao K, Chen Q-J, Deng F, Liu L-L, Yan B, Zhan F-X, Wang Y-Y, Xiao G-F, Si Z-L. A pneumonia outbreak associated with a new coronavirus of probable bat origin. Nature 2020;579:270-3. https://doi.org/10.1038/s41586-020-2012-7

[13] WHO. Novel Coronavirus (2019-nCoV). Situation Report - 22. 11 February 2020. Available at: https://www.who.int/docs/ default-source/coronaviruse/situation-reports/20200211-sitrep22-ncov.pdf?sfvrsn=fb6d49b1_2 (retrieved on 13 March 2020).

[14] Shi J, Wen Z, Zhong G, Zhong G, Yang H, Wang C, Huang B, Liu R, He X, Shuai L, Sun Z, Zhao Y. Susceptibility of ferrets, cats, dogs, and other domesticated animals to SARScoronavirus 2. Science 2020;368:1016-20. https://doi. org/10.1126/science.abb7015

[15] Gobalenya AE, Baker SC, Baric RS, de Groot RJ, Drosten C, Gulyaeva AA, Haagmans BL, Lauber C, Leontovich AM, Neuman BW, Penzar D, Perlman S, Poon LLM, Samborskiy DV, Sidorov IA, Sola I, Ziebuhr J. The species severe acute respiratory syndrome-related coronavirus: classifying 2019-nCoV and naming it SARS-CoV-2. Nat Microbiol 2020;5:536-44. https://doi.org/10.1038/s41564-020-0695-Z

[16] Tang X, Wu C, Li X, Song Y, Yao X, Wu X, Duan Y. On the origin and continuing evolution of SARS-CoV-2. Natl Sci Rev 2020:nwaa036. https://doi.org/10.1093/nsr/nwaa036

[17] Andersen KG, Rambaut A, Lipkin WI, Holmes EC, Garry RF. The proximal origin of SARS-CoV- 2. Nat Med 2020;26:450-2. https://doi.org/10.1038/s41591-020-0820-9.

[18] Walls AC, Park YJ, Tortorici MA, Wall A, McGuire AT, Veesler D. Structure, function and antigenicity of the SARS-CoV2-2 spike glycoprotein. Cell 2020;181:281-92.e6. https://doi. org/10.1016/j.cell.2020.02.058

[19] WHO. Situation report 2020 on COVID-19. Available at: https:// www.who.int/docs/default-source/coronaviruse/situationreports/20200404-sitrep-75-covid-19.pdf?sfvrsn=99251b2b_2 (accessed on 05.04.2020).

[20] Banerjee S, Dhar S, Bhattacharjee S, Bhattacherjee P. Decoding the lethal effect of SARS-COV-2 (novel coronavirus) strains from global perspective: molecular pathogenesis and evolutionary divergence. bioRxiv 2020. https://doi. org/10.1101/2020.04.06.027854

[21] Yi Y, Lagniton P, Ye S, Li E, Xu RH. COVID-19: what has been learned and to be learned about the novel coronavirus disease. Int J Biol Sci 2020;16:1753-66. https://doi.org/10.7150/ ijbs. 45134

[22] Phan T. Genetic diversity and evolution of SARS-CoV-2. Infect Genet Evol 2020;81:104260. https://doi.org/10.1016/j. meegid.2020.104260

[23] Basu P, Bhattacharya S. A new dimension in the dengue epidemiology with special reference to the genetic diversity of the virus: a review. Int J Fauna Biol 2016;3:29-41.

[24] Von Hahn T, Yoon JC, Alter H, Rice CM, Rehermann B, Balfe P,McKeating JA. Hepatitis $C$ virus continuously escapes from neutralizing antibody and T-cell responses during chronic infection in vivo. Gastroenterology 2007;132:667-78. https:// doi.org/10.1053/j.gastro.2006.12.008

[25] Dimmock NJ, Easton AJ, Leppard K. Introduction to modern virology. Malden, MA: Blackwell Pub 2007.

[26] Guzman MG, Vazquez S. The complexity of antibody-dependent enhancement of dengue virus infection. Viruses 2020;2:264962. https://doi.org/10.3390/v2122649

[27] van der Hoek L, Pyrc K, Berkhout B. Human coronavirus NL63, a new respiratory virus. FEMS Microbiol Rev 2006;30:760-73. https://doi.org/10.1111/j.1574-6976.2006.00032.x

[28] Qiu H, Wu J, Hong L, Luo Y, Song Q, Chen, D. Clinical and 
epidemiological features of 36 children with coronavirus disease 2019 (COVID-19) in Zhejiang, China: an observational cohort study. Lancet 2020;20. https://doi.org/10.1016/S14733099(20)30198-5

[29] The epidemiological characteristics of an outbreak of 2019 novel coronavirus diseases (COVID-19) - China CCDC, February 17, 2020. Available at: https://weekly.chinacdc.cn/en/ article/id/e53946e2-c6c4-41e9-9a9b-fea8db1a8f51
[30] Mehta P, F McAuley DF, Brown M, Sanchez E, Tattersall RS, Manson JJ. COVID-19: consider cytokine storm syndromes and immunosuppression. Lancet 2020;395:1033-4. https://doi. org/10.1016/ S0140-6736(20)30630-9

[31] Chin AWH, Chu JTS, Perera MRA, Hui KPY, Yen H-L, Chan MCW, Peiris M, Poon LLM. Stability of SARS-CoV-2 in different environmental conditions. Lancet Microbe 2020. https://doi.org/10.1016/ S2666-5247(20)30003-3

Received on April 21, 2020. Accepted on May 18, 2020.

Correspondence: Probal Basu, Tomas Bata University in Zlin, 76001 Zlín, Czech Republic - Tel. +420 576038120 - E-mail: probalbasu2010@ gmail.com

How to cite this article: Bhattacharya S, Basu P, Poddar S. Changing epidemiology of SARS-CoV in the context of COVID-19 pandemic. J Prev Med Hyg 2020;61:E130-E136. https://doi.org/10.15167/2421-4248/jpmh2020.61.2.1541

(c) Copyright by Pacini Editore Srl, Pisa, Italy

This is an open access article distributed in accordance with the CC-BY-NC-ND (Creative Commons Attribution-NonCommercial-NoDerivatives 4.0 International) license. The article can be used by giving appropriate credit and mentioning the license, but only for non-commercial purposes and only in the original version. For further information: https://creativecommons.org/licenses/by-nc-nd/4.0/deed.en 